\title{
Recurrent Diastema Closure after Orthodontic Treatment with Ceramic Veneers: About A Case Report
}

\author{
Mohamed Amine Hdiji ${ }^{1}$, Rihab Dakhli ${ }^{2 *}$, Yosra Farhat ${ }^{1}$, Zohra Nouira $^{3}$, Mounir Cherif ${ }^{3}$
}

\author{
${ }^{1}$ Resident, Department of Fixed Prosthodontics, Dental Faculty of Monastir, University of Monastir, Tunisia \\ ${ }^{2}$ Associate Professor, Research Laboratory of Occlusodontics and Ceramic Prosthesis LR16ES15, Faculty of Dental Medicine, \\ University of Monastir, Monastir, Tunisia \\ ${ }^{3}$ Professor, Department of Fixed Prosthodontics, Faculty of Dental Medicine, University of Monastir, Monastir, Tunisia
}

DOI: $10.36347 /$ sjds.2021.v08i03.003

| Received: 27.02.2021 | Accepted: 05.03.2021 | Published: 06.03.2021

*Corresponding author: Rihab Dakhli

\section{Abstract}

Since anterior spaces may interfere with smile attractiveness and compromise dento-facial harmony, diastema closure is a challenging procedure for clinicians. The purpose of this article was to describe the closure of a maxillary median diastema of a 21-year-old man, with lateral incisor agenesis that had undergone orthodontic treatment as a young teenager and due to his lack of motivation during the retention phase a reopening of middle diastema was detected. The therapeutic approach was to make four ceramic veneers.

Keywords: Diastema, agenesis, relapse, space closure, veneers, glass ceramic.

Copyright $\odot 2021$ The Author(s): This is an open-access article distributed under the terms of the Creative Commons Attribution 4.0 International License (CC BY-NC 4.0) which permits unrestricted use, distribution, and reproduction in any medium for non-commercial use provided the original author and source are credited.

\section{INTRODUCTION}

Tooth agenesis is one of the most common abnormalities in the development of the dentition, it manifests by the absence of one or multiple teeth. Literature has shown that the most frequently missing teeth were the maxillary lateral incisors, followed by the mandibular second premolars and the mandibular central incisors [1].

Upper lateral incisor plays a significant role in patient's smile and has an obvious impact on facial aesthetics and self-esteem that's why the demand of aesthetic improvement is higher when it is concerned by agenesis [2].

In this case, the orthodontic solution is either space closure or space opening for prosthetic replacements or implant. Moreover, they both compromise aesthetics, periodontal health, and function but also time consuming [3].

Mostly, patients treated with orthodontic space closure were more satisfied with the appearance of their teeth than those having prosthesis, owing to the general impression of artificial in comparison with natural teeth [4].

Although, the stability of orthodontic space reopening of spaces in the anterior part of the mouth can be shown, especially when the permanent retainer bonded to maxillary dentition is debonded and the patients miss their periodic check-ups during the retention phase of orthodontic treatment [5].

However, when a patient has already been through an orthodontic treatment the idea of retreatment will certainly not be appealing. The patient might be resistant to the idea, although the diastema is troubling, and the correction seems necessary for aesthetic reasons. Therefore, space closure by porcelain veneers seems to achieve patient's assumption because it does not only mimic natural structure of dental element and guaranties color stability but also it ensures tissues preservation and a minimal preparation [6].

This clinical report presents the case of a patient with anterior diastema after orthodontic relapse who was treated by porcelain veneers.

\section{CASE REPORT}

A 21 years old patient presented in our department with multiple anterior spaces. Clinical examination revealed that he had undergone orthodontic treatment within the past 3 years and due to his lack of motivation, he lost periodic check-up during the retention period. 
A brief evaluation of his medical history indicated that before orthodontic treatment he had upper lateral incisor agenesis, which was handled by space closure. X-ray examination showed normal anterior maxillary teeth and periapical condition.

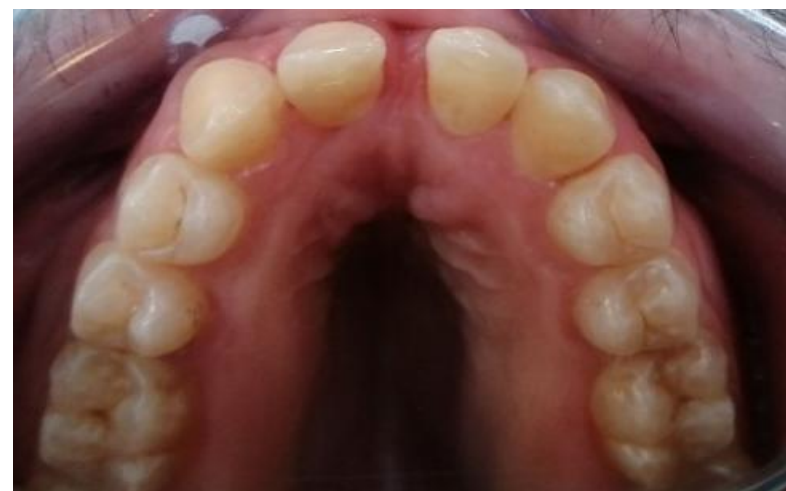

Fig-1: Frontal view showing a 3 to $4 \mathrm{~mm}$ midline diastema

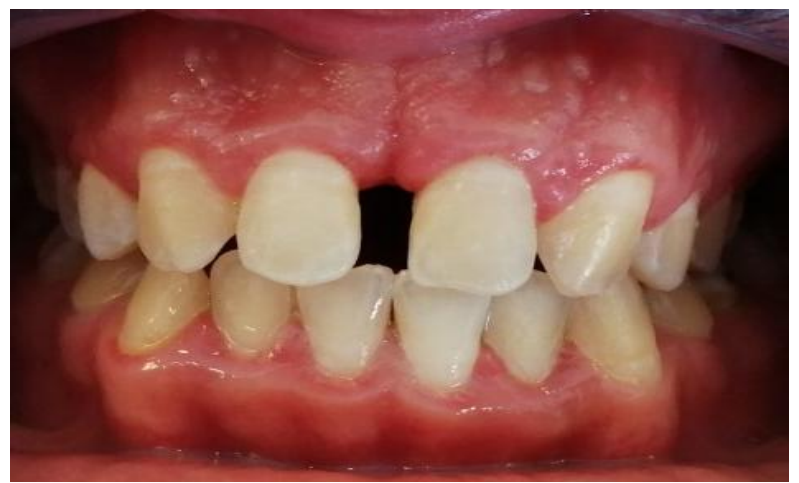

Fig-2: Occlusal view showing spaces between maxillary central incisors, and between lateral incisors and canines

At the first appointment, intraoral photographs were taken to analyse the cosmetic aspects of the case [Figure 1,2] and first impression was taken for study models.

A combination of orthodontic and restorative treatment was proposed to the patient. However, he rejected the idea of orthodontic retreatment. Thus, a diagnostic wax-up was made [Figure 3], followed by a diagnostic mock-up with a self-cured temporary composite material (Structure Premium, VOCO GmbH, Cuxhaven, Germany) in order to evaluate the future dimensions of the proposed veneers [Figure 4]. Seeing the result, the patient was satisfied, checked the aesthetic rendering and asked to move forward.

A putty reduction guide matrix (Hydrorise Putty, Zhermack SpA, and Badia Polesine, Italy) was fabricated in order to evaluate incisal and facial reduction [Figure 5a, 5b].

At the second session, conservative tooth preparations were made followed by polishing and smoothing [Figure 5c, 5d]. Then, final impression was made using light-body and heavy-body consistency polyvinylsiloxane (Virtual 380, Ivoclar Vivadent, and Amherst, NY, USA).

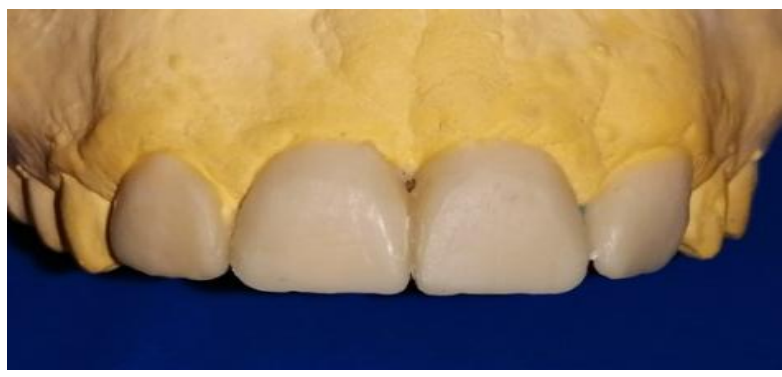

Fig-3: Diagnostic wax-up model

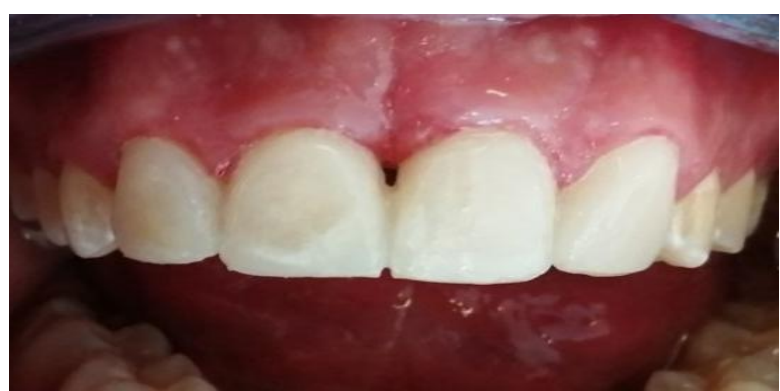

Fig-4: Diagnostic mock-up

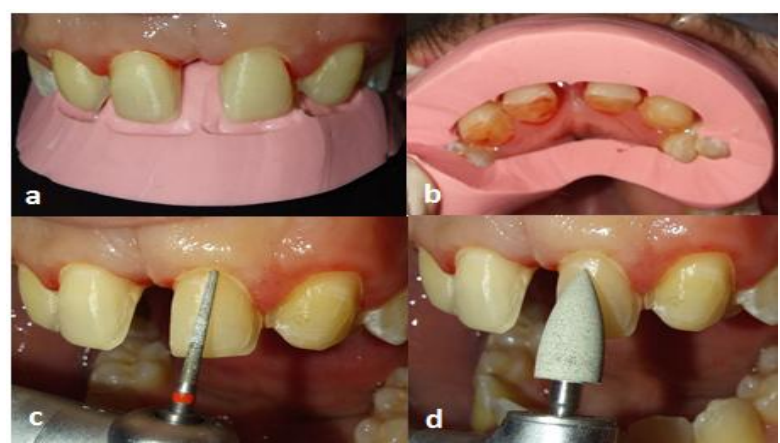

Fig-5: $(a, b, c)$ the preparation must remain within the enamel structure controlled using the putty reduction guide matrix (a- facial and b-occlusal view) and (c) finally polished and smoothened before taking impression

In laboratory, Porcelain veneers were made from pressed ceramic (IPS Empress ${ }^{\circledR}$ Esthetic, E TC-1 ceramic ingot; Ivoclar/Vivadent, Schaan, Liechtenstein) with a layering of veneering ceramic to mimic the halo enamel.

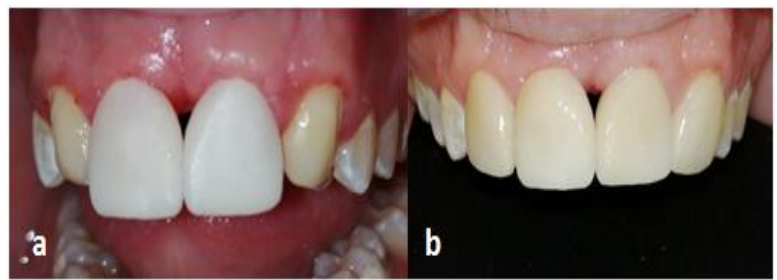

Fig-6: Evaluation of the veneer color using different shades of try-in paste, (a) try-in bleach, (b) try-in clear

At the next appointment, just before bonding we evaluate the marginal fit, occlusion and final shape of veneers and Try-in of ceramic restorations was 
Mohamed Amine Hdiji et al., Sch J Dent Sci, Mar, 2021; 8(3): 98-101

performed with light and neutral try-in pastes (Variolink Esthetic Try-in, Ivoclar Vivadent) [Figure 6].

Once the cement color (color A2) was chosen, pieces were prepared for cementation. First, Isolation was provided with a rubber dam from 15 through 25 [Figure 7a].

Ceramic veneers were etched by hydrofluoric acid surface treatment (IPS Ceramic Etching Gel, Ivoclar Vivadent) for 60 seconds followed by rinsing and drying. After that, silane (Monobond-S, Ivoclar Vivadent) was applied for 60 seconds, and then the restoration was dried. The tooth surface was first treated with $37 \%$ phosphoric acid gel (Condac, FGM) for 30 seconds [Figure 7b], then rinsed, and dried.

The adhesive system (Syntac-ivoclar) was applied for 30 seconds. The light color cement (Variolink Esthetic LC, Ivoclar Vivadent) was applied to both veneers for 11 and 21 [Figure 7c], which were placed onto the teeth [Figure 7d]. Excess cement was removed with a micro brush and floss in the interproximal surfaces before light curing for 20 seconds on the facial surface. The same sequence was followed for the teeth and veneers on 13 and 23 . Finally, a glycerin layer (Liquid Strip, Ivoclair Vivadent) was applied between the union piece and tooth, and resin cement was light cured for another 20 seconds, aiming at blocking the oxygen entrance. The patient was very satisfied with his new smile [Figure 8].

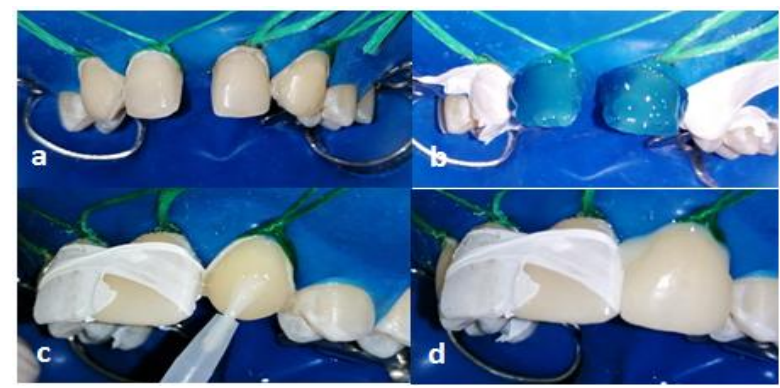

Fig-7: Bonding procedure (a) Rubber dam isolation, (b) etching the enamel surface with phosphoric acid $37 \%$ for 30 seconds, (c) application of the adhesive system (d) fitting the veneer after applying a thin layer of luting cement

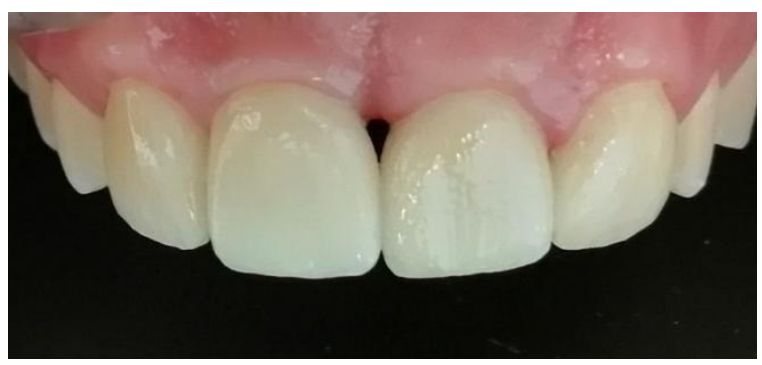

Fig-8: The final restoration

\section{DISCUSSION}

Orthodontic retention is a critical stage of orthodontic treatment and seeks to maintain the teeth in their corrected positions after the achievement of orthodontic movements. Actually about $50 \%$ of patient experience relapses after space closure [7].

Studies showed that midline diastema closure is highly unstable [8]. In fact, Midline diastema relapse was statistically significant in most studies while lateral diastemas showed great stability [9]. Adding to that, unfortunately, patient compliance often decreases as orthodontic treatment progresses and low compliance with retention appliances can often ruin the improvements achieved during treatment.

Regarding diastema closure there is a variety of materials and techniques to achieve aesthetic results. The strategy is to respect the gradient therapeutic concept and to start with the least invasive solution. Once orthodontic retreatment was rejected by the patient, restorative approach using composite resin represents a suitable alternative, it is commonly used in minimally invasive restorations because it required minimal tooth preparation and has excellent adhesion to enamel with a reported overall survival rate of over $88 \%$ after 10 years [10].

However, we should mention that color instability of composite resin due to water absorption leads to aesthetic degradation of the restoration. Likewisethe, size of the restoration leads to failure due to the unstable position of composite resin [11].

In the other side, ceramic veneers provide also an appropriate restorative solution with exceptional biocompatibility, longevity, function, aesthetics, and periodontal health [6].

Nevertheless, to achieve the desired aesthetic and optimum function, careful treatment planning and proper tooth preparation design are essential. Therefore, the preservation of enamel is vital for the long-term success of ceramic veneers, which require an optimal bond between the veneer and tooth structure. Thus, it is ideal for preparations to remain within the enamel structure [12].

Pressed systems are more suitable for this situation, this is built on the fact that glass-ceramic have high survival rates, higher strength and fracture toughness than powder/liquid systems (porcelain). Adding to that, the less porosity of the materiel, the high concentration of crystals and casting under heat and constant pressure increases the tightness of the particles and makes the material much denser [13]. 
Mohamed Amine Hdiji et al., Sch J Dent Sci, Mar, 2021; 8(3): 98-101

\section{CONCLUSION}

The closure of anterior spaces involves often a multidisciplinary approach, such as orthodontic treatment, periodontal evaluation and restorative treatment in order to have aesthetic results. Nevertheless, it is primordial to start with the least invasive treatment to be the most conservative for dental tissue. Ceramic veneer seems to be a suitable treatment with higher expectancy, longevity and satisfying aesthetic result.

\section{Conflict of Interests}

The authors declare that there is no conflict of interests regarding the publication of this paper.

\section{REFERENCES}

1. Celikoglu M, Kazanci F, Miloglu O, Oztek O, Kamak H, Ceylan I. Frequency and characteristics of tooth agenesis among an orthodontic patient population.

2. Robertsson S, Mohlin B. The congenitally missing upper lateral incisor. A retrospective study of orthodontic space closure versus restorative treatment. The European Journal of Orthodontics. 2000 Dec 1;22(6):697-710.

3. Silveira GS, de Almeida NV, Pereira DM, Mattos CT, Mucha JN. Prosthetic replacement vs space closure for maxillary lateral incisor agenesis: a systematic review. American Journal of Orthodontics and Dentofacial Orthopedics. 2016 Aug 1;150(2):228-37.

4. Nordquist GG, McNeill RW. Orthodontic vs. restorative treatment of the congenitally absent lateral incisor-long term periodontal and occlusal evaluation. Journal of Periodontology. 1975 Mar;46(3):139-43

5. Kartal Y, Kaya B. Fixed orthodontic retainers: a review. Turkish journal of orthodontics. 2019 Jun;32(2):110.
6. Farias-Neto A, Gomes EM, Sánchez-Ayala A, Sánchez-Ayala A, Vilanova LS. Esthetic rehabilitation of the smile with no-prep porcelain laminates and partial veneers. Case reports in dentistry. 2015 Oct 18;2015.

7. Littlewood SJ, Kandasamy S, Huang G. Retention and relapse in clinical practice. Australian dental journal. 2017 Mar;62:51-7.

8. MORAIS JF, FREITAS MR, FREITAS KM, Janson G, CASTELLO BRANCO N. Postretention stability after orthodontic closure of maxillary interincisor diastemas. Journal of Applied Oral Science. 2014 Oct;22(5):409-15.

9. Shashua D, Årtun J. Relapse after orthodontic correction of maxillary median diastema: a followup evaluation of consecutive cases. The Angle Orthodontist. 1999 Jun;69(3):257-63.

10. Cosenza H, Pamato S, Vermudt A, Pereira JR. Interdisciplinary approach using composite resin and ceramic veneers to manage an esthetic challenge. The Journal of prosthetic dentistry. 2020 Mar 18.

11. Farias-Neto A, Gomes EM, Sánchez-Ayala A, Sánchez-Ayala A, Vilanova LS. Esthetic rehabilitation of the smile with no-prep porcelain laminates and partial veneers. Case reports in dentistry. 2015 Oct 18;2015.

12. Aslan YU, Uludamar A, Özkan Y. Clinical performance of pressable glass- ceramic veneers after 5, 10, 15, and 20 years: A retrospective case series study. Journal of Esthetic and Restorative Dentistry. 2019 Sep;31(5):415-22.

13. Morimoto S, Albanesi RB, Sesma N, Agra CM, Braga MM. Main Clinical Outcomes of Feldspathic Porcelain and Glass-Ceramic Laminate Veneers: A Systematic Review and Meta-Analysis of Survival and Complication Rates. International Journal of Prosthodontics. 2016 Jan 1;29(1). 